\title{
Tied up in red tape, European trials shut down
}

The chemotherapy drug doxorubicin has been used to treat soft-tissue cancers in children for more than 20 years, but doctors don't know the most effective dose, nor how it interacts with other drugs.

In 2005, European researchers set out to find

these answers in a large, multi-center trial.

Two years on, fewer than half of the 600 participants needed have been recruited. Only 2 of the 16 countries originally involved-Italy and France-began on time. Denmark has yet to start, and Poland, Austria, Sweden and Germany - the last expected to provide 25\% of study subjects - dropped out. Trial coordinators canceled plans to analyze data part way through the study. The trial's 2010 end date is likely to be pushed back by at least two years.

Scientists say the study is merely the latest victim of the Clinical Trials Directive, implemented by the European Union in May 2004 to make trials safer and more consistent. The directive, aimed largely at holding pharmaceutical companies to higher standards, has tied up academic clinical research, particularly large trials, with redundant paperwork, liability tangles and unending bureaucracy.

"The directive has caused a huge headache," says Kathy Pritchard-Jones, European branch president of the International Society of Paediatric Oncology. "We're starting to see holes in the research portfolio."

The cost of academic cancer trials has doubled since 2004, according to Cancer Research UK, the country's largest sponsor of academic cancer research. The European Organization for the Research and Treatment of Cancer estimates that expenses have risen by $85 \%$ and says the number of trials it supports has dropped by $63 \%$. The Save European Research campaign, which represents more than 3,000 scientists, says academic drug trials have dropped by $70 \%$ in Ireland and $25 \%$ in Sweden. The number of Finnish academic drug trials shrunk by $75 \%$.

Because the directive is technically not law, each of the European Union's 27 member countries was free to set it up differently, creating vast differences in rules across countries.

"In France, they told me that we couldn't include ethnic groups as a category in our database," says Gianni Bisogno, a pediatric oncologist at the Hospital of Padova in Italy. "We had to change the database, which meant more time, more money."

More problematic than those logistical details, researchers say, is the patchwork of requirements for reporting adverse events.

In Germany, for instance, investigators must file a report on every unexpected adverse event in each of a trial's centers, as well as relevant information produced by any researcher in the world who studies the same treatment.

\section{TRIAL AND ERROR}

The European Clinical Trials Directive has created bureaucratic nightmares and is shutting down trials. Since the directive's launch:

Increase in the cost of academic cancer trials in the UK

Drop in academic drug trials in Finland

Drop in academic trial submissions

in Ireland

Increase in the cost of trials

supported by EORTC

New trials supported in 2004 by the group

New trials supported in 2005 by the group

Sources: Cancer Research UK; Brit. Med. J.; EORTC

“They're getting overwhelmed with the amount of paper they've got to sift through," says Pritchard-Jones. She adds that truly important adverse events may get overlooked in the pile.

The biggest bottleneck, researchers say, is the directive's requirement that each trial have a single sponsor assume full legal and financial liability.

"There are not many institutions willing to take responsibility," says Mariana Resnicoff, coordinator of the European Science Foundation's collaborative research program.

The European Commission is studying how to fix the directive, spokesman Ton van Lierop said in an email. "If not properly addressed, [the problems] may impact negatively in the fulfillment of the directive."

Brandon Keim, New York

\section{Ambitious scheme for developing world trials in 'big trouble'}

When the European and Developing Countries Clinical Trials Programme (EDCTP) was formed in 2003, some public health experts worried that the pan-European scheme would conflict with national research programs. Others wondered whether its emphasis on AIDS, malaria and tuberculosis would cause other diseases to be neglected.

Four years later, with the program's fourth executive director set to take office, those fears seem naively optimistic.

With a $€ 600$ million budget, the EDCTP is the largest European sponsor of developingworld drug trials. But it has thus far funded only eight trials. Staff turnover, grant squabbles and communications breakdowns have plagued the program, and its potential remains largely unfulfilled.
"The EDCTP is certainly in big trouble," says Mario Raviglione, director of the World Health Organization's Stop TB partnership.

Although $€ 87$ million was reserved for future grant calls, just $€ 24$ million has been awarded so far. Complaints over the program's first round of grants led in September 2004 to the ouster of its thenexecutive director, Piero Olliaro. The next call for grants was released only in early 2006. By October, Odile Leroy, the third director in as many years, had stepped down to head the European Malaria Vaccine Initiative.

The board in January approved Charles Mgone, the Tanzanian-born head of the program's African office as its next director.

The high staff turnover and organizational bureaucracy has left some would-be partners, including Raviglione, unsure of whom to contact on important matters. No one from the program has ever contacted Stop TB, Raviglione adds. "I simply have no idea what they're doing, and when I ask around, not many people know what's going on over there," he says.

Cynthia Naus, the program's operations manager, says staff have worked with the WHO on non-tuberculosis projects. The director of the WHO's Tropical Diseases Program is also an observer on the main strategizing group, she adds.

"The EDCTP has had a slow start, but it was also an organization that was literally built from scratch," Naus says. "We do realize the urgency."

Brandon Keim, New York 